\title{
Riscos ambientais na atividade do lixador autônomo industrial
}

Environmental risks in independent industrial activity sander

\author{
Cristian Emilio Montenegro do Nascimento', Carlos Enrique de M. Jerônimo² \\ Cacilda Alves de Sousa' \\ 'Especialista em Engenharia de Segurança do Trabalho (UnP) \\ ${ }^{2}$ Prof. Doutor da Universidade Potiguar (UnP)
}

\begin{abstract}
Resumo
O presente trabalho buscou focar os estudos dirigidos sobre as atividades desenvolvidas pelos autônomos lixadores na indústria de montagem da cidade de Mossoró-RN, cujo foco principal foi à produção montagem e manutenção de equipamentos. O objetivo foi identificar e analisar os agentes físicos calor e ruído principalmente a qual os lixadores estão expostos, propondo medidas para diminuir as consequências danosas e aos possíveis riscos, propondo-se à implantação de medidas preventivas e de engenharia aplicadas a indústria. Quanto à metodologia utilizada tratou-se de uma pesquisa exploratória quantitativa com pesquisa de campo e a finalidade ou naturezas participantes. De acordo com o que se precisa, buscou-se avaliar com cuidado diversos fatores, para que fosse possível fazer uma associação do desempenho desta atividade a um ambiente mais saudável aos colaboradores da indústria de montagem, através da aplicação de checklist e análises (análise preliminar de riscos), utilizando-se aparelhos específicos como o decibelímetro e medidor de estresse térmico, dessa forma coletando assim informações e avaliando as atividades dos colaboradores para classificarmos e adicionarmos medidas de controles eficientes para minimizar ou anular os danos físicos, visando proporcionar uma melhor qualidade laboral dos funcionários que exercem essa atividade no seu cotidiano.
\end{abstract}

Palavras-chaves: Indústria de Montagem. Condições Ambientais. Avaliação.

\begin{abstract}
The present work looked to focus the studies directed on the activities developed by the autonomous sanders in industry assembly city Mossoró-RN, whose main focus was the production assembly and maintenance of equipment. The goal was to identify and analyze the physical agents heat and noise which mainly sanders are exposed, proposing measures to reduce the harmful consequences and possible risks, proposing the implementation of preventive measures applied and engineering industry. Regarding the methodology used was treated for an exploratory field research with quantitative and objective natures or participants. According to what we need, we sought to carefully evaluate several factors, it was possible to make a combination of the performance of this activity to a healthier environment for employees of industrial assembly, by applying checklist and analysis, using specific devices like the decibel meter and thermal stress, thereby collecting information and thereby evaluating the activities of employees to qualify and add effective control measures to minimize or negate the physical damage, aiming to provide a better quality of labor officials who carry this activity in their daily lives.
\end{abstract}

Keywords: Assembly of Industry. Environmental Conditions. Evaluation. 


\section{INTRODUÇÃO}

A introdução da máquina a vapor, sem sombra de dúvida, mudou integralmente o quadro industrial. Condições totalmente inóspitas de calor, ventilação e umidade eram encontradas, pois as "modernas" fábricas nada mais eram que galpões improvisados. O trabalho em máquinas sem proteção; o trabalho executado em ambientes fechados onde à ventilação era precária e o ruído atingia limites altíssimos; a inexistência de limites de horas de trabalho; trouxeram como consequência elevados índices de acidentes e de moléstias profissionais (PORTAL ABS, 2012). Entretanto, esse cenário não foi tão duradouro, tendo sido substituído por um novo modelo, cultuado pela engenharia da segurança ocupacional.

No novo modelo, os agentes ambientais tendem a serem envolvidos, sejam eles elementos ou substâncias presentes nos diversos ambientes humanos que, quando encontrados acima dos limites de tolerância, podem causar danos à saúde das pessoas. Além disso, outras fontes relativas aos riscos ambientais do cenário industrial têm vinculo com os agentes mecânicos, agentes físicos, agentes biológicos e os agentes Ergonômicos. Conforme, descreve Ayres (2001), esse conjunto de elementos deve ser a base para o desenvolvimento de programas e na visão prevencionista para eliminação dos problemas com a saúde dos trabalhadores.

No tocante aos agentes físicos, que serão envolvidos como elemento principal deste trabalho, esses são conceituados por Saliba (2011), como sendo os riscos gerados pelos agentes que têm capacidade de modificar as características físicas do meio ambiente. Atualmente, as atividades profissionais que envolvem riscos físicos continuam ameaçando a saúde do trabalhador, como exemplo, o ruído e o calor, que estão envolvidos em diferentes atividades profissionais.

No contexto de uma das principais indústrias de transformação, que envolve os cenários metalúrgicos e os consumidores finais, como o caso da indústria do petróleo, surge a figura dos profissionais do processo de lixamento. Que se envolvem em diferentes patamares de riscos e prejuízos a saúde. Entretanto, poucos são os relatos que desdobram tais patamares e que qualificam os cenários para um bom planejamento da gestão de saúde e segurança ocupacional.

Logo, quando se tem uma avaliação rigorosa baseada em parâmetros sobre as análises ambientais do ambiente de trabalho, no qual existem grandes potenciais de riscos que prejudicam os colaboradores, atenua-se os índices de acidentes e se garante que os resultados das avaliações quantitativas de ruído e calor sejam direcionados para aplicação de medidas preventivas e exposição de sugestões de melhorias para obtenção de um ambiente seguro de forma salubre.

Ademais, o ambiente de trabalho no qual possibilita a exposição continua de pressão sonora bastante elevada, são os que mais prejudicam a saúde do trabalhador no ambiente ocupacional, pois devido o pouco investimento nas maquinas $\mathrm{e}$ equipamentos da indústria faz com que apareçam condições de irregularidades e esse problema pode ser evidenciado de forma permanente ou parcial, e também devido à falta de aplicação medidas de controle diretamente na fonte geradora de ruído, treinamentos de utilização correta dos equipamentos de segurança, informação dos riscos que o mesmo estar exposto e a não utilização dos equipamentos de proteção individual - EPI.

Diante desse cenário, neste trabalho busca-se a apresentação de um modelo que possa apoiar à satisfação, a saúde, a segurança e a qualidade de vida, de profissionais envolvidos com atividades metalúrgicas no universo do município de Mossoró, quase sempre associados a prestação de serviços para a indústria petrolífera. Para tal, foi realizado um levantamento preliminar dos riscos das atividades vinculadas e realizadas algumas medições quanto à exposição de agentes derivados do ruído e de fontes térmicas naturais e artificiais.

\section{REFERENCIAL TEÓRICO}

\section{I ANÁLISE PRELIMINAR DE RISCOS - APP}

A Análise Preliminar de Perigos (APP) consiste no método indutivo e é estruturada para detectar os potenciais perigos que decorrem da instalação de novas unidades e sistemas desconhecidos ou do próprio funcionamento da planta que opera com materiais perigosos. Este método tem como objetivo analisar as formas pelas quais os componentes do processo podem atuar fora de controle e de forma inesperada, elencando, para cada situação de perigos identificada, as causas, as formas de detecção disponíveis e as consequências sobre os trabalhadores, tanto no entorno na população como sobre o meio ambiente. Em seguida é executada uma avaliação qualitativa dos riscos relacionados, identificando-se, desta maneira, aqueles que necessitam ser priorizados. Além disso, a título de sugestão, incluem-se medidas mitigadoras sobre os riscos, com a finalidade de 
eliminar os agentes causais ou diminuir as consequências nos sistemas com acidentes identificados (ALENCAR, 2009).

A estrutura da APP envolve os eventos considerados perigosos cujas fontes tenham origem no sistema analisado, envolvendo tanto as falhas de materiais ou do sistema, como eventuais erros de operação ou de manutenção (falhas humanas). $\mathrm{O}$ resultado final de uma APP consiste na identificação dos perigos e no mapeamento das áreas perigosas com base nos cenários de acidente relativos aos processos, armazenamentos, instalações, transportes de produtos químicos e a outros sistemas inerentes aos processos industriais.

O uso da APP, conforme descreve Camacho (2004), associada com matrizes de aceitabilidade de risco exige que os cenários de acidente sejam classificados em categorias de frequência, as quais fornecem uma indicação qualitativa da frequência esperada de ocorrência para os cenários identificados. Esta escolha dos critérios é função do tipo de análise que se pretende executar, podendo ser definida pela entidade governamental ou pela própria empresa, quando se tratar de estudo interno.

A indústria do setor de montagem e manutenção de equipamentos, não tem definido um cenário de monitoração e qualidade do ambiente de trabalho, que possam subsidiar programas de proteção auditiva, programas de prevenção de riscos ambientais, laudos técnicos de condições ambientais de trabalho, mas através da análise sobre a realidade da empresa, pode ser de suma importância à implantação de uma política de segurança no trabalho, para eliminar ou minimizar riscos aos colaboradores e qualquer outra parte interessada que possam estar expostas aos riscos de doenças associados a sua atividade, dessa forma proporcionando uma melhor qualidade de vida e de trabalho dos funcionários.

Segundo a NR- 9 no item 9.1. PPRA, visando à preservação da saúde e da integridade dos trabalhadores, através da antecipação, reconhecimento, avaliação e consequente controle da ocorrência de riscos ambientais existentes ou que venham a existir no ambiente de trabalho, tendo em consideração a proteção do meio ambiente e dos recursos naturais

A identificação de riscos ambientais é de extrema importância, principalmente quando implantado o Programa de Prevenção de Riscos Ambientais - (PPRA), pois esse projeto identifica os principais potenciais críticos e age através de sugestões e medidas para serem aplicadas para melhoria do ambiente:

De acordo com Kerzner (2001), o primeiro passo para identificar os riscos é detectar as áreas potenciais de risco, sendo que através da eficácia desta identificação resultará a eficiência do gerenciamento de risco.

Para isso, algumas etapas devem ser qualificadas para um melhor aproveitamento e planejamento do PPRA, a saber:

- Identificar os riscos no ambiente de trabalho.

- A determinação e localização das possíveis fontes geradoras;

- A identificação das possíveis trajetórias e dos meios de propagação dos agentes no ambiente de trabalho;

- A identificação das funções e determinação do número de trabalhadores expostos;

- A caracterização das atividades e do tipo da exposição;

- A obtenção de dados existentes na empresa, indicativos de possível comprometimento da saúde decorrente do trabalho.

- Os possíveis danos à saúde relacionados aos riscos identificados, disponíveis na literatura técnica;

- No caso desta avaliação quantitativa deverá ser realizada sempre que necessária para:

- Comprovar o controle da exposição ou a inexistência riscos identificados na etapa de reconhecimento;

- Dimensionar a exposição dos trabalhadores;

- Subsidiar o equacionamento das medidas de controle.

As analises realizadas in loco, através da aplicação de cheklist, e medições de ruído e calor no local de trabalho, com o propósito de obter informações para realizar um diagnóstico. E com os resultados, será aplicada a regulamentação dos programas referente à saúde do trabalhador na indústria que se encontra em estudo.

Os riscos ambientais a serem levantados, na concepção de Ayres; Correa (2001) são os derivados dos agentes físicos, químicos, biológicos, ergonômicos e de acidentes/mecânicos que possam trazer ou ocasionar danos à saúde do trabalhador nos ambientes de trabalho. Sherique (2004) complementa esta definição afirmando que para que esses agentes sejam considerados fatores de riscos ambientais os mesmos precisam estar presente no ambiente de trabalho, porém em 
determinada concentração e intensidade e tempo de exposição ao agente.

De acordo, ainda, com a Norma Regulamentadora $n^{\circ} 9$ (NR-9) do Ministério do Trabalho e Emprego (MTE), considera-se riscos ambientais os agentes físicos, químicos e biológicos existentes nos ambientes de trabalho, que, em função de sua natureza, concentração ou intensidade e tempo de exposição, são capazes de causar danos à saúde do trabalhador. Há ainda os riscos ergonômicos, gerados principalmente pela postura irregular dos profissionais de enfermagem em situações como movimentações de pacientes, flexões da coluna frequentes, entre outros. Já os riscos de acidentes são aqueles inerentes a cada ambiente de trabalho, como, por exemplo, risco de queda decorrente de pisos ou iluminação inadequados (SESI-SEBRAE, 2005).

Sendo assim, para o desenvolvimento do presente trabalho foi convencionado que o conceito de riscos físicos deve ser representado por fatores ou agentes existentes no ambiente de trabalho que podem afetar a saúde dos trabalhadores, como: ruídos, vibrações, radiações, frio, calor, pressões anormais e umidade (SESI-SEBRAE, 2005). Para efeito de qualificação de cada um desses cenários considerou-se:

\section{FATORES FÍSICOS E ERGONÔMICOS NO AMBIENTE DE TRABALHO}

\section{I. VIBRAÇÃO}

Produzida por máquinas e equipamentos específicos, com o passar do tempo e sem a devida proteção, o trabalhador poderá sofrer danos nas articulações, dores na coluna, disfunção renal e circulatória (SESI-SEBRAE, 2005).

\subsection{RADIAÇÃO}

Como sendo originária da radiação ultravioleta, provocada por soldas elétricas, por exemplo, pode ocasionar lesões oculares e queimaduras. As ionizantes, advindas de materiais radioativos, podem provocar anemias, leucemia e até outros tipos de câncer (SESI-SEBRAE, 2005).

\subsection{RUIDO}

Gerada em níveis excessivos, os ruídos advindos no local de trabalho, ao longo do tempo podem provocar alterações auditivas, que vão desde a perda parcial até a surdez total (SESI-SEBRAE, 2005).

\subsection{CALOR}

Os trabalhadores expostos a atividades de fundição, siderurgia, indústrias de vidro a céu aberto e outras, são os mais propensos a problemas como insolação, câimbras e, em alguns casos, problemas com o cristalino do globo ocular, mais conhecidos como catarata (SESI-SEBRAE, 2005).

\subsection{FRIO}

Os casos mais comuns de doenças que se destacam pela ação do frio são as queimaduras pelo frio, gripes, inflamações das amígdalas e da laringe, resfriados, algumas alergias, congelamento nos pés e mãos e problemas circulatórios (SESI-SEBRAE, 2005).

\subsection{UMIDADE}

As atividades ou operações executadas em locais alagados ou encharcados, com umidade excessiva, poderão ser capazes de produzir danos à saúde dos trabalhadores, como frieiras e micoses, dentre outras (SESI-SEBRAE, 2005).

\subsection{FATORES ERGONÔMICOS}

Como riscos físicos, também, devem ser considerados os aspectos ergonômicos ligados à execução de tarefas, à organização e às relações de trabalho, ao esforço físico intenso, levantamento e transporte manual de peso, mobiliário inadequado, posturas incorretas, controle rígido de tempo para produtividade, imposição de ritmos excessivos, trabalho em turno e noturno, jornadas de trabalho prolongadas, monotonia, repetitividade e situações causadoras de estresse (SESI-SEBRAE, 2005).

\section{MATERIAIS E MÉTODOS}

O estudo constitui-se de uma pesquisa aplicada, pois objetiva levar conhecimentos para extensão do uso das principais técnicas e recomendações acerca da legislação dos programas de gerenciamento de riscos ambientais e na tratativa de casos fortuitos para os serviços de construção e montagem, no processo de lixamento, para instalações industriais.

Do ponto de vista dos objetivos, trata-se de um estudo exploratório-descritivo, o qual visa descrever a problemática em discussão, buscando caracterizar o objeto de estudo. Bem como, fazendo um estudo comparativo às pesquisas desenvolvidas para o monitoramento, gerenciamento e proposição de medidas mitigadoras dos riscos ambientais associados à atividade. 


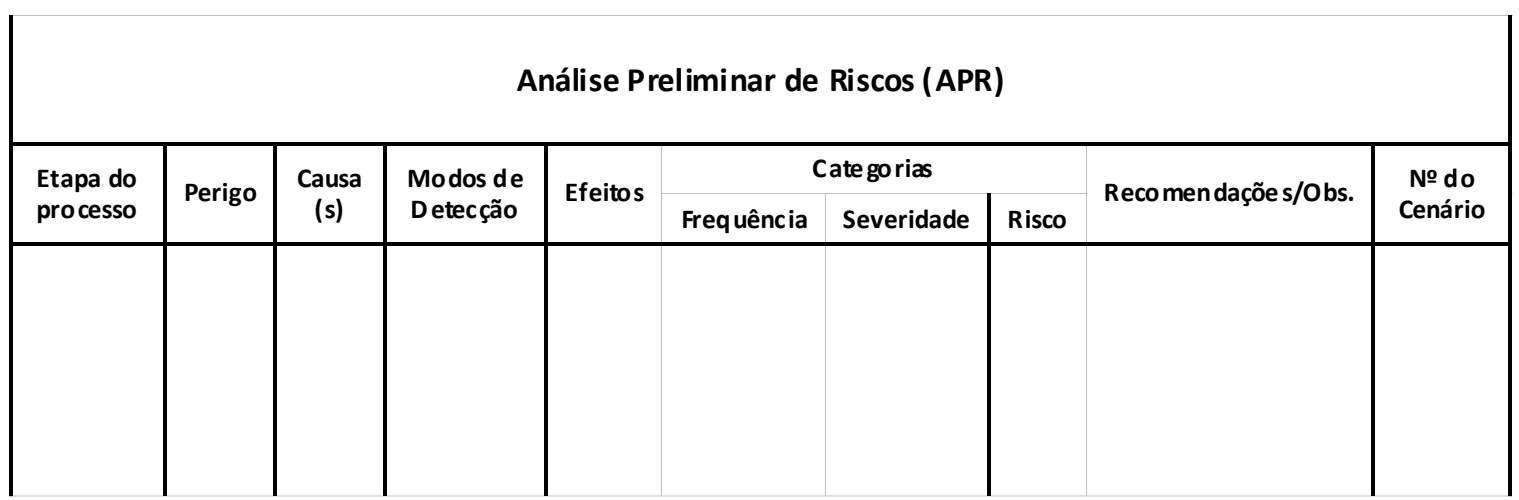

Figura 1: Planilha de Análise Preliminar de Riscos. Fonte: Autores.

A hipótese pauta-se na possibilidade de haver alterações significativas e riscos a saúde humana nos casos analisados, em especial, pela exposição excessiva aos agentes analisados. Em outras palavras, espera-se que essa análise demonstre elementos para apoiar no aumento dos níveis de eficácia dos sistemas de gestão de segurança e saúde ocupacional.

Do ponto de vista dos procedimentos técnicos, o estudo caracteriza-se como pesquisa bibliográfica, por sua elaboração partir do levantamento e análise de material já publicado, como artigos científicos, livros, relatórios técnicos, etc. e (Silva; Menezes, 2001), e como estudo de caso devido à utilização de dados de campo.

A estrutura da pesquisa consiste em:

- Formulação do problema, englobando a justificativa do estudo, a determinação dos objetivos, a contextualização da problemática e definição da metodologia;

- Realização do levantamento teórico, que orienta a caracterização do objeto de estudo, as definições e conceitos a serem utilizados em análise e correntes de pensamentos que norteiam a hipótese da pesquisa;

- Levantamento de dados em campo, por meio de incursões investigativas em empresas que atuam com atividades de lixamento, mais especificamente do estado do Rio Grande do Norte;

- Estudo criterioso sobre o cumprimento dos requisitos atribuídos pela Norma Regulamentadora do Ministério do Trabalho e Emprego (MTE) de número 9;

- Realização de uma análise estatística dos dados obtidos e desdobramento numa análise preliminar de riscos.

Os dados coletados em campos foram organizados, de acordo com a necessidade da utilização em pesquisa, e utilizados para elaboração do levantamento das principais ações de oportunidades.

A metodologia de APR utilizada compre- ende a execução das seguintes etapas: definição dos objetivos e do propósito da análise; definição das fronteiras do processo analisado; levantamento de campo para coleta de informações sobre a instalação e os perigos envolvidos; subdivisão do processo em etapas; realização da APR propriamente dita (preenchimento da planilha); caracterização dos cenários identificados através de uma matriz de classificação de risco (frequência e severidade) e análise dos resultados (Aguiar, 2011).

Os resultados da APR foram registrados convenientemente numa planilha, conforme ilustrado na Figura 1. Que, para cada etapa do processo, mostra os perigos identificados, as causas, o modo de detecção, efeitos potenciais, categorias de freqüência, severidade e risco, as medidas corretivas e/ou preventivas e o número do cenário (Amorim, 2010).

Para a execução da análise, o processo em estudo foi dividido em etapas. A realização da análise propriamente dita é feita através do preenchimento de uma planilha de APR para cada atividade do fluxograma de processo do segmento. A planilha adotada para a realização da APR, mostrada na Figura 2, contém nove colunas, as quais devem ser preenchidas conforme as descrições a seguir:

\section{I. PERIGO}

Identificaram-se, para cada etapa do processo, os respectivos perigos. De uma forma geral, os perigos são eventos acidentais que têm potencial para causar danos às instalações, aos operadores, ao público ou ao meio ambiente.

\subsection{CAUSAS}

Discriminaram-se as causas de cada perigo. Estas causas podem envolver tanto falhas intrínsecas de equipamentos (vazamentos, rupturas, falhas de instrumentação, etc.), bem como erros humanos de operação e manutenção. 


\subsection{MODO DE DETECÇÃO}

Relacionaram-se os modos disponíveis na instalação para a detecção do perigo identificado.

\subsection{EFEITO}

Listaram-se os possíveis efeitos danosos de cada perigo identificado.

\subsection{CATEGORIAS DE FREQUÊNCIA}

Definiu-se como "cenário de acidente" o conjunto formado pelo perigo identificado, suas causas e cada um dos seus efeitos. Deste modo, classificaram-se cada cenário de acidente em uma categoria de freqüência, a qual fornece uma indicação qualitativa da probabilidade esperada de ocorrência para cada cenário identificado, conforme a Tabela 1 (Amorim, 2010).

\subsection{CATEGORIAS DE SEVERIDADE}

Classificaram-se cada cenário de acidente em categoria de severidade, a qual fornece uma indicação qualitativa do grau de severidade das consequências de cada um dos cenários identificados. As categorias de severidade utilizadas no presente trabalho estão discriminadas na Tabela 2 (Amorim, 2010).

Tabela 1: Categorias de Freqüência dos Cenários da APR.

\begin{tabular}{|c|c|c|}
\hline Categoria & Denominação & Descrição \\
\hline 1 & $\begin{array}{l}\text { Extremamente } \\
\text { Remota }\end{array}$ & $\begin{array}{l}\begin{array}{l}\text { Extremamente improvável de ocorrer durante a vida útil da } \\
\text { instalação }\end{array} \\
\end{array}$ \\
\hline 2 & Remota & Não deve ocorrer durante a vida útil da instalação \\
\hline 3 & Improvável & Pouco provável que ocorra durante a vida útil da instalação \\
\hline 4 & Provável & $\begin{array}{l}\text { Esperado ocorrer pelo menos uma vez durante a vida útil da } \\
\text { instalação }\end{array}$ \\
\hline 5 & Freqüente & $\begin{array}{l}\text { Esperado ocorrer várias vezes durante a vida útil da } \\
\text { instalação }\end{array}$ \\
\hline
\end{tabular}

Fonte: Adaptado de Amorim (2010).

Tabela 2: Categorias de Severidade dos Cenários da APR.

\begin{tabular}{|c|c|c|}
\hline Categoria & Denominação & Descrição/Características \\
\hline I & Desprezível & $\begin{array}{l}\text { Não ocorrem lesões ou mortes de funcionários, de terceiros } \\
\text { (não funcionários) e/ou de pessoas extramuros (indústrias e } \\
\text { comunidade); o máximo que pode ocorrer são casos de primeiros } \\
\text { socorros ou tratamento médico menor. }\end{array}$ \\
\hline II & Marginal & $\begin{array}{l}\text { Lesões leves em funcionários, terceiros e/ou em pessoas } \\
\text { extramuros; }\end{array}$ \\
\hline III & Crítica & $\begin{array}{l}\text { Lesões de gravidade moderada em funcionários, em terceiros e/ } \\
\text { ou em pessoas extramuros (probabilidade remota de morte de } \\
\text { funcionários e/ou de terceiros); exige ações corretivas imediatas } \\
\text { para evitar seu desdobramento em catástrofe. }\end{array}$ \\
\hline IV & Catastrófica & $\begin{array}{l}\text { Provoca mortes ou lesões graves em várias pessoas (em } \\
\text { funcionários e/ou em pessoas extramuros); }\end{array}$ \\
\hline
\end{tabular}

Fonte: Adaptado de Amorim (2010). 


\subsection{CATEGORIA DE RISCO}

Combinando-se as categorias de frequência com as de severidade obtêm-se a Matriz de Riscos, conforme a Figura 2, a qual fornece uma indicação qualitativa do nível de risco de cada cenário identificado na análise. $\mathrm{O}$ resultado dessa matriz permite visualizar os cenários de acidente de maior impacto para a segurança do processo. (Amorim, 2010).

\subsection{MEDIDAS/OBSERVAÇÕES}

Esta coluna contém as medidas que devem ser tomadas para diminuir a freqüência ou severidade do acidente ou quaisquer observações pertinentes ao cenário de acidente em estudo.

\subsection{IDENTIFICADOR DO CENÁRIO DE ACIDENTE}

Esta coluna contém um número de identificação do cenário de acidente. Foi preenchida seqüencialmente para facilitar a consulta a qualquer cenário de interesse, conforme Figura 2.

A metodologia utilizada para o levantamento e medições foi à observação in loco, no ambiente de trabalho no qual é desenvolvido a atividade dos lixadores, onde se realizou um diagnóstico da indústria de montagem e manutenção de equipamentos, no que se referiu à segurança e saúde dos colaboradores do setor industrial da cidade de Mossoró/RN.

De acordo com a NHO-06, se aplica à exposição ocupacional ao calor em ambientes internos ou externos, com ou sem carga solar direta, em quaisquer situações de trabalho, não estando, no entanto, voltada para a caracterização do conforto térmico.

Dentre os métodos de análise a exposição ao calor considerou-se a comparação às normas internacionais ACGIH - American Conference of Governmental Industrial Hygienists, NIOSH - National Institute of Occupational Safety \& Health. Entretanto, é importante saber que é de fundamental importância da compreensão e colaboração do empregador em atender com todas as normas regulamentadoras dimensionadas pelo Ministério do Trabalho e Emprego - MTE.

\begin{tabular}{|c|c|c|c|c|c|c|c|}
\hline & \multicolumn{5}{|c|}{ Frequência } & \multirow{8}{*}{$\begin{array}{l}\text { Seve } \\
\text { rida } \\
\text { de }\end{array}$} & \multirow{2}{*}{$\begin{array}{l}\text { Legenda } \\
\text { Risco }\end{array}$} \\
\hline A & B & C & D & $E$ & & & \\
\hline \multirow{2}{*}{2} & \multirow{2}{*}{3} & \multirow{2}{*}{4} & \multirow{2}{*}{5} & \multirow{2}{*}{5} & \multirow{2}{*}{ IV } & & 1 - Desprezível \\
\hline & & & & & & & 2 - Menor \\
\hline \multirow[t]{2}{*}{1} & \multirow[t]{2}{*}{2} & \multirow[t]{2}{*}{3} & \multirow[t]{2}{*}{4} & \multirow[t]{2}{*}{5} & \multirow[t]{2}{*}{ III } & & 3 - Moderado \\
\hline & & & & & & & 4 - Sério \\
\hline 1 & 1 & 2 & 3 & 4 & II & & 5 - Crítico \\
\hline 1 & 1 & 1 & 2 & 3 & I & & \\
\hline
\end{tabular}

Figura 2: Matriz de Classificação de Riscos usada na APR. Fonte: Camacho (2005) e Amorim (2010)

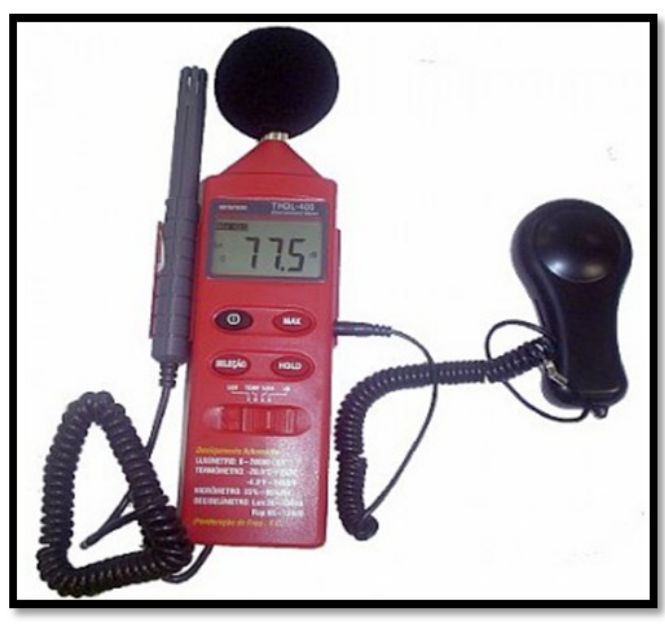

Figura 3: Termômetro de Globo (INSTRUTHERM)

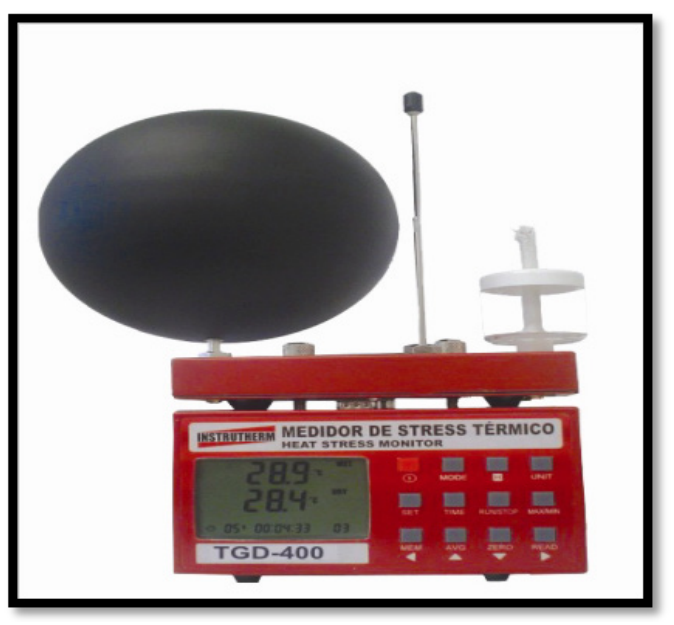

Figura 4: Decibelímetro (INSTRUTHERM) 
Para análise quantitativa de calor foi utilizado o instrumento Termômetro de Globo Digital (conforme Figura 3) marca INSTRUTHERM, modelo TGD-400. Composto de indicador e módulo-sensor com quatro sondas indica a temperatura de globo, bulbo seco, bulbo úmido, velocidade do ar e efetua o cálculo de IBUTG interno e externo do ambiente a ser avaliado.

Para avaliação do Ruído foi utilizado um Decibelímetro - Medidor de Nível de Pressão Sonora Digital (conforme Figura 4) modelo: THDL - 400, marca INSTRUTHERM.

\section{RESULTADOS E DISCUSSÃO}

\section{I. AGENTE FÍSICO: SOBRECARGA TÉRMICA}

A avaliação dos níveis de exposição ao calor no ambiente de trabalho do lixador foi desenvolvida através da utilização do "Índice de Bulbo Úmido - Termômetro de Globo" (IBUTG), previsto na Norma Regulamentadora $\mathrm{N}^{\circ} 15$ (Atividades e Operações Insalubres) - Anexo $\mathrm{N}^{\circ} 3$ (Limites de Tolerância para Exposição ao Calor) da Portaria 3.214 de 08 de junho de 1978.

O IBUTG é um índice de Sobrecarga Térmica definido por uma equação matemática que correlaciona todos os parâmetros ambientais, ou seja, temperatura, umidade do ar, velocidade do ar, calor radiante e o tipo de atividade desenvolvida pelo trabalhador. A atividade desenvolvida pelo trabalhador era lixador, ficava no ambiente interno sem carga solar, conforme equações a seguir:

\section{IBUTG: 0,7 TBN + 0,3 TG}

TBN: temperatura de bulbo úmido natural TG: temperatura de globo

Com relação às medidas encontradas nas investigações em campo, foram aferidos os valores médios de TBN: $38,5^{\circ} \mathrm{C}$ e TG: $38,0{ }^{\circ} \mathrm{C}$, tendo-se um valor para o IBUTG: $0,7 \cdot 38 \cdot 5+0,3 \cdot 38,0=$ $38,3^{\circ} \mathrm{C}$. Ou seja, conforme Quadro $\mathrm{N}^{\circ} 3$ do Anexo $\mathrm{N}^{\circ} 3$ da NR 15 (Portaria 3.214 do MTE de 8 de junho de 1978), o tipo de atividade desenvolvida é considerada moderada (de pé, trabalho leve em máquina ou bancada, com alguma movimentação). Além disso, nesse cenário, de acordo com o Quadro $\mathrm{N}^{\circ} 1$ do Anexo $\mathrm{N}^{\circ} 3$ da NR 15 (Portaria 3.214 do MTE de 8 de junho de 1978), não é permitido o trabalho, sem a adoção de medidas adequadas de controle num tipo de atividade moderada num ciclo de trabalho contínuo acima de $26,7^{\circ} \mathrm{C}$.

O levantamento quantitativo do IBUTG foi realizado próximo à bancada onde o mesmo realiza o serviço com a lixadeira, das $13 \mathrm{~h} 15$ às 14h00min. Durante a medição tivemos a percepção que o trabalhador por um determinado tempo faz movimentos repetitivos de forma agachada. $\mathrm{O}$ IBUTG (Índice de Bulbo Úmido e Termômetro de Globo) obtido foi de $38,3^{\circ} \mathrm{C}$. Considerando o valor de $6,62^{\circ} \mathrm{C}$ acima do limite de tolerância, o cenário descreve que lixador fica cerca de 30 minutos executando seu trabalho e tem como descanso apenas 05 minutos, a atividade é considerada moderada. Na Tabela 3, são apresentadas as medições nos diferentes ciclos de rotinas de trabalho.

Esse cenário envolve uma série de efeitos ao organismo devido à exposição ao calor tais como: desidratação; Erupção da pele; Câimbras; Fadiga física; Distúrbios psiconeuróticos; Problemas cardiocirculatórios e Insolação. Logo, é importante salientar que a atividade do lixador é considerada como insalubre, pois não atende o quadro de número 1, 2 e 3 do anexo $\mathrm{n}^{\circ} 3$ da NR-15.

Com base nos resultados obtidos é possível recomendar as seguintes melhorias para o referido cenário, a saber:

Limitação do tempo de exposição: Adotar um período de descanso para o trabalhador, visando reduzir a sobrecarga térmica a níveis compatíveis com o organismo. Neste caso índice analisado (IBUTG), é medida de controle quantitativa sendo sempre necessária. Quando os tempos de exposição não forem compatíveis com as condições de

Tabela 3: Medidas termométricas obtidas (oC)

\begin{tabular}{|c|c|c|c|c|}
\hline Termômetro & $\begin{array}{c}\text { 10 Ciclo } \\
\text { 10h15min }\end{array}$ & $\begin{array}{c}\text { 2o Ciclo } \\
\text { 10h30min }\end{array}$ & $\begin{array}{c}\text { 30 Ciclo } \\
\text { 10h40min }\end{array}$ & $\begin{array}{c}\text { 40 Ciclo } \\
11 \mathrm{~h} 00 \mathrm{~min}\end{array}$ \\
\hline TG & 38,8 & 38,0 & 37,4 & 38,4 \\
\hline TBN & 38,8 & 38,0 & 38,4 & 38,3 \\
\hline IBUTG interno & 38,8 & 38,0 & 37,9 & 38,3 \\
\hline
\end{tabular}


trabalho observadas, deve-se promover um reestudo dos procedimentos de trabalho, no sentido de determinar um regime de trabalho-descanso que atenda os limites recomendados pela norma regulamentador NR-15.

Exames médicos: É obrigatória a realização de exames médicos admissionais com a finalidade de se detectar possíveis problemas de saúde do funcionário que possam ser agravados com a exposição ao calor, sendo eles: deficiências glandulares, sudoríparas, problemas cardíacos, fadiga e estresse.

\subsection{AGENTE FÍSICO: RUÍDOS}

De acordo com os anexos 01 e 02 da NR-15, o qual trata dos limites de tolerância para ruído contínuo ou intermitente. A atividade ou operações insalubres que exponham o trabalhador a níveis de ruído contínuo ou intermitente inferiores aos limites de tolerância fixados pelas normas. Neste trabalho, a análise quantitativa de pressão sonora foi desenvolvida em um galpão onde existe trabalho continuo ou intermitente. O aparelho foi ajustado para o circuito de compensação "A" e circuito de resposta lenta (SLOW). Utilizou-se o instrumento Decibelímetro a Digital modelo: THDL - 400 marca Instrutherm. Segundo estimativa do NIOSH [2001c], nos E.U.A. será perto de 30 milhões os trabalhadores expostos ao ruído no local de trabalho.

É possível identificar que nos dias atuais existem milhares de pessoas trabalhando, seja de forma direta ou indireta, mais todas exposta a determinados níveis de pressão sonora, sendo que os lixadores que trabalham com vinculo empregatício estão atuando diante situações de segurança precária, devido à falta de conhecimento dos empregadores sobre a importância do investimento na área de segurança no trabalho e o retorno que os mesmo trarão para empresa, seja ela na diminuição de acidente e também um aumento na produtividade, pois com a redução de acidentes consequentemente diminuirá o tempo de funcionários afastados, fazendo com que o mesmo desempenhe sua atividade de forma integral da carga horária e aumentando a satisfação dos trabalhadores. Esses impactos advindos do ruído envolvem: Aumento das tensões; Irritabilidade; Aumento do medo; Redução à atenção; Redução da concentração; Aumento da susceptibilidade; Aumento da frequência cardíaca; Fadiga e Perturbação da visão.

As avaliações realizadas apresentaram níveis de pressão sonora variáveis entre 99,0 dB(A) a 110,00 $\mathrm{dB}(\mathrm{A})$, sendo o nível de pressão sonora cerca de 104,5 dB(A). De acordo com as eviden- cias encontrada foi possível verificar que poucos fazem uso dos EPI's tipo Protetor auditivo do tipo plug de silicone, que é reutilizável e composto de três flanges de tamanhos diferentes que se ajusta no canal auditivo, e mediante análise de identificação do CA (Certificado de Aprovação) N 5674, pelo Ministério do Trabalho e Emprego o mesmo atenua $15 \mathrm{~dB}(\mathrm{~A})$.

Com base nos resultados obtidos é possível recomendar as seguintes melhorias para o referido cenário, a saber:

- Eliminação e/ou substituição por máquinas mais silenciosas

- Implementar barreiras sonoras

- Silenciadores

- Redução do tempo de exposição

- Modificação do ritmo de funcionamento da máquina

- Suporte antivibratórios

- Equipamentos de Proteção Individual - EPI

\section{CONCLUSÃO}

É importante considerar que a indústria em geral, inicialmente deverá fazer vinculo com seus colaboradores que atuam de forma autônoma de acordo com a legislação vigente no país, posteriormente deverá obter conhecimento dos riscos que os trabalhadores estão expostos e possivelmente perceber a necessidade de adequar-se conforme normas regulamentadoras, através de documentações, que evidenciam tais ações, diante disso deve-se mudar toda a visão e entender de que segurança no ambiente de trabalho é sempre considerada um custo, mais sim um investimento, trazendo muitas vantagens favoráveis aos empregados, assim como para o desenvolvimento tecnológico da empresa.

Evidenciou-se que as avaliações quantitativas no ambiente de trabalho dos lixadores com o âmbito de identificar possíveis riscos de ruído e calor, conforme primeira obtenção de dados avaliados, que o local onde o trabalhador executa suas atividades não estava de acordo com anexo $\mathrm{N}^{\circ} 01$ da NR-15, fazendo com que a área onde o mesmo desenvolvia suas tarefas fosse considerada insalubre, devido não atender os parâmetros legais da legislação vigente e por não existir medidas de controle e também pelo simples fato do protetor auditivo não atenuar o nível sonoro para $85 \mathrm{~dB}$ (A), no qual é o valor permitido no período de 8 horas diárias e os resultados de calor ultrapassaram os limites de tolerância previsto no quadro $\mathrm{n}^{\circ} 1$ do anexo $\mathrm{n}^{\circ} 03$ da NR-15, pois o regime de trabalho 
do lixador era de 50 minutos de trabalho e 10 minutos de descanso, mesmo a atividade sendo considerada como moderada o resultado obtido foi de $38,3{ }^{\circ} \mathrm{C}$ e conforme anexo não é permitido o trabalho, em temperaturas superiores a 31,1 ${ }^{\circ} \mathrm{C}$, sem a adoção de medidas adequadas de controle. De acordo com análise in loco, conclui-se que a atividade é considerada insalubre, dando direito ao lixador receber o devido adicional de insalubridade de grau médio, conforme norma regulamentadora NR-15.

\section{REFERÊNCIAS}

AGUIAR, L. A. Metodologias de Análise de Riscos APP \& Hazop. Rio de Janeiro: 2011. Disponível em: $<$ http://professor.ucg.br/SiteDocente/admin/arquivosUpload/13179/material/APP_e_HAZOP.pdf>. Acesso em: 06 jul. 2012.

ALENCAR, L. Metodologias de análise de riscos: APP e HAZOP. Rio de Janeiro: UFRJ, 2009, 30f. Disponível em <http://www.saneamento.poli.ufrj. br>. Acesso em 21/06/2012.

ALMEIDA, W. F. De. Trabalho Agrícola e sua Relação com Saúde/Doença. Rio de Janeiro, 1995.

AMORIM, E. L. C. de. Ferramentas de Análise de Risco. Apostila do curso de Engenharia Ambiental da Universidade Federal de Alagoas, CTEC, Alagoas: 2010. Disponível em: < http://pt.scribd.com/ doc/71505557/Apostila-de-ferramentas-de-analise-de-risco>. Acesso em: 08 jul. 2012.

AYRES, D. de O.; CORREAA, J. A. P. Manual de Prevenção de Acidentes do Trabalho. São Paulo, Editora ATLAS, 2001.

CAMACHO, E. N. Uma Proposta de Metodologia para Análise Quantitativa de Riscos Ambientais. (2004). Tese - Programa de Pós-graduação de Engenharia, Universidade Federal do Rio de Janeiro, 2004.

COUTO, J. L. V. do. Segurança no trabalho rural (2007). Disponível em: <http://www.ufrrj.br/institutos/it/de/acidentes/acidente.htm > Acesso em: 2 de julho de 2012.

INSTRUTHERM. Disponível em: http://www.instrutherm.com.br/instrutherm. Acesso: 23 de agosto de 2012.
IBP. Informações e Estatísticas. Disponível em: <http://www.ibp.org.br>. Acesso em: 11/07/2012.

INDUSTRIAL HYGIENISTS - ACGIH - Documentation of the threshold limit and biological exposure indices. 6. ed. Cincinnati, Estados Unidos, 1996.

KERZNER, Harold. Project Management: a systems approach to planning, SCHEDULING, and controlling. United States, John Wiley \& Sons, 2001.

KOLESNIKOVAS, C. et al. Avaliação de risco toxicológico para hidrocarbonetos totais de petróleo em forma fracionada aplicada à gestão e monitoramento de água subterrânea em um complexo industrial. Águas Subterrâneas, v.23, n.01, p.31-44, 2009.

MINISTÉRIO DA SAÚDE DO BRASIL. Doenças relacionadas ao trabalho: manual de procedimentos para serviços de saúde. Ministério da Saúde do Brasil, Representação no Brasil da OPS/OMS. Brasília: Ministério da Saúde, 2001.

MINISTÉRIO DO TRABALHO E EMPREGO. Portaria ${ }^{\circ} 3.214$, de 08 de junho de 1978. NR-6: Equipamento de proteção individual, Brasília, DF, 2012.

MINISTÉRIO DO TRABALHO E EMPREGO. Portaria $n^{\circ} 3.214$, de 08 de junho de 1978. NR-31: Segurança e saúde no trabalho na agricultura, pecuária silvicultura, exploração florestal e aqüicultura, Brasília, DF, 2012.

NIOSH - National Institute for Occupational Safety and Health (2001c) Work-related hearing loss, DHHS Publication No. 2001-103, USA.

PORTAL ABS disponível em: http://portal.abs.org. br/estudos/conceitos-gerais-sobre-seguranca-no-trabalho.htm Acesso em: 20 de agosto de 2012.

SALIBA, T. M. Curso Básico de Segurança e Higiene Ocupacional. 4. ed. São Paulo: LTR, 2011.

SESI-SEBRAE. Dicas de Prevenção de Acidentes e Doenças no Trabalho. SESI -SEBRAE, Saúde e Segurança no Trabalho : Micro e Pequenas Empresas / Luiz Augusto Damasceno Brasil (org.). - Brasília: SESI-DN, 2005.

SHERIQUE, Jaques. Aprenda como fazer: PPRA, PCMAT E MRA. São Paulo: LTR, 2004. 
SILVA, J. R. et al. Protocolo de ações preventivas aos riscos ocupacionais presentes em indústrias de produção sucroalcooleira. Revista Eletrônica de Enfermagem do Centro de Estudos de Enfermagem e Nutrição [serial on-line] 2011 ago-set 2(2):1-16. Available from: <http://www.ceen.com.br/revistaeletronica>.

YIN, R. Estudo de caso: planejamento e métodos. Porto Alegre: Bookman, 2005. 